Rev. Latinoam. Psicopat. Fund., São Paulo, 19(2), 214-224, jun.2016

http://dx.doi.org/10.1590/1415-4714.2016v19n2p214.2

\title{
Conferência/Lecture
}

\section{Habitar, construir, existir: algunas consideraciones sobre el cuerpo en las psicosis*1}

Sonia Leite*2

Desde Freud, Lacan y de un importante texto de Heidegger, que se ocupa del tema del habitar, se destaca la cuestión de la inscripción del cuerpo - la primera morada - desde el encuentro con el Otro. La ausencia del significante de la falta impide el psicótico de, en ciertas situaciones, apropiarse del sentido desencadenando la psicosis. La invención del cuerpo propio es una vía de rescate de la ruptura de la realidad y de la estabilización en las psicosis.

Palabras clave: Cuerpo, psicosis, espacio, estabilización

${ }^{* 1}$ El trabajo, presentado en las III Jornadas Internacionales de Hermenéutica, en 2013, en la ciudad de Buenos Aires, es resultante de los debates mantenidos en el Taller Clínico y de Investigación sobre las Psicoses, del Centro Psiquiátrico Rio de Janeiro (Leite, 2009) que cuenta con la participación de compañeros y residentes del referido Centro y de alumnos de graduación y de postgrado de la Universidade do Estado do Rio de Janeiro - UERJ (Rio de Janeiro, RJ, Br).

*2 Universidade do Estado do Rio de Janeiro - UERJ (Rio de Janeiro, RJ. Br). 
Heidegger (1954/2008) en el importante ensayo Construir, habitar, pensar plantea dos provocadoras cuestiones: ¿Qué es habitar? ¿En qué medida el habitar pertenece al construir? Según indica, de pronto, parece que sólo es posible habitar lo que se construye, sin embargo, no todas las construcciones son de hecho moradas, y se evidencia que solamente algunas construcciones le ofrecen al hombre una verdadera protección. Por otro lado, señala que no todas las moradas cargan la garantía de que ahí ocurre un habitar. Sugiere, entonces, que busquemos en la etimología de las palabras, construir y habitar, una referencia a la esencia de la cuestión, ya que "el hombre se comporta como si él fuera creador y dueño del lenguaje, y el leguaje, a la vez, permanece siendo el dueño del hombre" (Heidegger, 1954/2008, p. 126). Es decir, el modo por el que entendemos las palabras está siempre imbuido por factores que superan la individualidad y que se articula siempre a factores sociales, históricos, culturales que determinan la vida humana. El referido autor resalta, incluso, que es algo de "nuestra época" suponer que habitar y construir sean dos actividades por separado.

La palabra del alto alemán antiguo empleada para decir construir (buan) - que se perdió a lo largo del tiempo - significa, originariamente, habitar, permanecer, vivir. Desde esta perspectiva, señala que "construir ya es, por sí mismo, habitar" (Heidegger, 1954/2008, p. 126). Incluso, "la manera como Tú eres y Yo soy, o sea, el modo por el cual somos hombres sobre esa tierra es el habitar (buan) (...). En ese sentido, la antigua palabra construir dice que el hombre es en la medida en que habita" (p. 127). Porque ser y estar sobre la tierra es lo que desde siempre es lo habitual. 
El filósofo lo considera algo fundamental para el tema aquí discutido. La transformación semántica en el ámbito propio de la palabra bauen (habitar) indica algo decisivo: “(...) el hecho de no hacerse la experiencia de que habitar constituye el ser del hombre y de que no se piensa, en sentido pleno, que habitar es el rasgo fundamental del ser-hombre" (p. 128). Es sólo en la medida en que habita que el hombre puede edificar lugares y articular espacios.

Lo que se destaca en ese bello ensayo es que no existe una oposición entre el hombre y el espacio. "El espacio no es un objeto exterior, tampoco una vivencia interior" (p. 137). Lo que se verifica, por ejemplo, cuando pensamos en un puente; en este momento ya estamos junto a aquel puente allá, "(...) y no, simplemente, junto a un contenido de representación almacenado en nuestra conciencia" (p. 137).

Aunque aparentemente lejos de una temática clínica, tales cuestiones contribuyen demasiado a una reflexión acerca de la problemática de las psicosis y su tratamiento. Dicha temática se vuelve provocadora al revelar la ausencia de lugar vivida por el sujeto psicótico, cuando el cuerpo propio pierde la consistencia imaginaria y la articulación simbólica, ocasionando la experiencia de estar sin protección y de ser penetrado por lo que le es externo. Dichos fenómenos se expresan, por ejemplo, por la sensación de que el Otro está mirándolo, de tener invadidos sus pensamientos, de escuchar voces, hecho que impone ciertas acciones convirtiendo al sujeto en una especie de prisionero de lo externo. Lo que se explicita es la importancia de la imagen del cuerpo en la constitución del sujeto.

¿Cómo se hace un cuerpo?

Tales cuestiones conducen al tema de la realidad que, según indica Lacan (1959-1960/1988), es el punto fundamental en el que se sitúan la fuerza y la novedad del psicoanálisis, en comparación con las demás ciencias humanas, en la medida en que introduce la necesaria distinción entre la realidad psíquica y lo real.

El psicoanálisis parte de la premisa de que el ser humano está marcado desde el inicio por el desamparo y por la dependencia con relación al Otro. Ese Otro que se escribe con mayúscula implica un campo simbólico que antecede a la existencia del sujeto y supera la idea de otro en cuanto semejante, pues incluye la diferencia y la alteridad. Es el lenguaje que se presenta por la palabra 


\section{CONFERÊNCIA/LECTURE}

y por la imagen del Otro que permite al niño apropiarse de lo que le es externo a él, encontrando, así, un lugar propio en el mundo.

El deseo es el deseo del Otro, como indica Lacan, que siguiendo inicialmente una perspectiva hegeliana va a depurar, introduciendo la noción de deseo inconsciente (Rabinovich, 2005). El sujeto se constituye como humano, es decir, como ser del lenguaje, a partir de las marcas del deseo del Otro primario. Y es el hecho de ese Otro ser necesariamente imperfecto en los cuidados que la no totalidad es también transmitida, posibilitando que la falta sea experimentada, en cierta medida, desde los orígenes del sujeto. Falta de totalidad, de lo completo, que significa falta del objeto.

No se trata de que sujeto sea simplemente capaz de desear cualquier cosa, sino de desear el deseo del Otro, deseo que inicialmente se presenta como deseo de reconocimiento. El deseo del deseo ya exige la presencia de uno más, que va más allá de la relación dual primaria, que le permite al niño significar la presencia y ausencia del sujeto materno incluyéndose, así, en el mundo del sentido. Este hecho convierte al niño en un ser capaz de experimentar la angustia proveniente de la falta del objeto, que de otra forma se cristalizaría en lo traumático y en el sinsentido (Leite, 2011).

Lacan (1957-1958/1999) denomina de metáfora paterna el momento crucial en que el enigmático deseo materno es descifrado por el niño, o sea, cuando dicho deseo gana un sentido — más allá de sí mismo — al articularse al significante Nombre del Padre, cuya ley impone una barrera al incesto. En otras palabras, convertirse en un ser de la cultura, encontrando un lugar social, significa estar sometido a la ley de prohibición del incesto que implica el reconocimiento de la imposibilidad de satisfacción absoluta, ya que el objeto primario es imposible. Siguiendo la tradición freudiana (Freud, 1924/1977c), que considera la cuestión de la pérdida de la realidad no sólo en la psicosis, sino también en la neurosis, lo que aquí se señala es que lo real es incognoscible. En otras palabras, aunque el acceso al lenguaje le permita al sujeto la creación del sentido, algo insiste y retorna más allá de la ley del lenguaje como sinsentido.

Es el trabajo psíquico que se efectiva desde el deseo del Otro, lo que recubre, en cierta medida, lo real en cuanto imposibilidad de satisfacción absoluta, permitiendo alguna consistencia para el ser. Tenemos como ejemplo el fantasear que crea un espacio interno privado - un teatro privado, como indica Freud - permitiendo no sólo la ilusión de la satisfacción, sino una delimitación entre lo interno y lo externo, constituyendo un territorio cuyo fundamento es la imagen del cuerpo propio. 
Desde este punto de vista, el desencadenamiento de la psicosis revela, entre otras cosas, el desmoronamiento de ese territorio y la imposibilidad de reconstrucción de la realidad psíquica desde las representaciones existentes. Resulta un fracaso observar los signos de la realidad, con los cuales el sujeto podría identificarse y cuya apropiación permitiría un posicionamiento en el mundo. Dicho fracaso tiene como causa la ausencia del significante Nombre del Padre (Lacan, 1957-1958/1999), que introduce la falta en cuanto constitutiva de la realidad psíquica.

Lacan (1954/1998b) ya había llamado la atención, a partir del análisis del artículo freudiano, La negativa (Freud, 1925/1977d), para la distinción entre el juicio de atribución y el juicio de existencia, en la constitución del sujeto. Es este último que involucra la representación de la realidad posibilitando el reencuentro del objeto que fundamenta el principio de la realidad.

En síntesis, el texto freudiano de 1925 trata de dos decisiones principales o dos puntos relacionados a la función del juzgamiento: afirmar o no la propiedad de un atributo particular (juzgamiento de atribución) y aseverar o discutir si una representación tiene o no existencia en la realidad (juzgamiento de existencia). La primera forma de juzgamiento está relacionada al yo-placer y la segunda al yo-realidad. En el último caso, no se trata de saber sólo si algo será integrado o no al yo en función del atributo bueno o malo, sino "si algo que ya está representado en el yo puede redescubrirse también en la percepción (realidad)" (Freud, 1925/1977d, p. 298). Esta última forma de juzgamiento es fundamental para considerar la cuestión de las psicosis, pues, como indica Freud, “(...) el objetivo inicial e inmediato de la prueba de realidad no es encontrar en la percepción real un objeto que corresponda a lo representado, sino reencontrar tal objeto, convencerse de que él está allí” (p. 298).

En la medida en que no es posible la representación de una cantidad intolerable de estímulos que alcanzan, en un determinado momento, el sujeto, el recurso a la insatisfacción en cuanto defensa, también se inviabiliza. En este sentido, en el caso de las psicosis, se puede considerar que el principio del placer es vencido (Freud, 1938/1977f; 1938/2007b), o sea, tal cantidad inviabiliza la acción del yo de manera similar a un estímulo excesivo, que proviene del mundo externo. En este caso, la única defensa posible sería una cancelación de la relación del yo con la realidad (Freud, 1938/1977f, p. 231).

Lacan, al indicar la precariedad del yo en cuanto una construcción imaginaria, subraya la importancia del sujeto de apropiarse del campo simbólico, encontrando una posición en el mundo. Afirma que el loco (psicótico) es aquel que adhiere a ese imaginario en virtud de una imposibilidad de hacer 


\section{CONFERÊNCIA/LECTURE}

uso del significante de la falta. ${ }^{1}$ Dicha adherencia puede funcionar durante algún tiempo, hasta el momento en que un acontecimiento inesperado propicia la eclosión de la psicosis. Con el esfacelamiento del yo, que es un yo corporal, el sujeto se ve penetrado por lo que le es exterior, reduciéndose a ser objeto del Otro.

Esta omnipresencia del Otro absoluto es lo que revela Ana, una adolescente esquizofrénica que experimenta una posición imposible: no puedo pensar en cosas de sexo porque ellos giran mis ojos. No puedo ver, no puedo pensar. No tengo salida: o me muero o me vuelvo loca.

En la esquizofrenia, a diferencia de la paranoia ${ }^{2}$ es necesario inventar soluciones que puedan delinear una relación con el cuerpo, construyendo así alguna barrera al Otro invasor. Es lo que revela el caso de José, que sólo consigue trabajar en locales en los que se le exige el uso del uniforme: mono, gorra y gafas. Llevar uniforme ejemplifica aquí la idea freudiana, presentada en el artículo El inconsciente (Freud, 1915/1977b), de que en la esquizofrenia las palabras son tratadas como cosas. O sea, vestir un uniforme no sólo representa algo como, por ejemplo, pertenecer a una empresa u organización de trabajo, sino que produce en realidad, no real, una forma unificada del cuerpo - (un) ser uniforme - por la utilización de elementos reales que construyen algún enlazamiento de las partes del cuerpo.

Mientras el mono le duplica la propia piel, es decir, reforzando esta línea divisoria entre el que está dentro y el que está fuera, la gorra permite una relación de la cabeza con el resto del cuerpo. A su vez, las gafas lo protegen de la mirada del otro que penetra su cabeza y su mente. Ocurre aquí una solución mínima (Miller, 2003), un punto de estabilización desde la construcción de una reconexión con las partes disyuntivas del cuerpo. La gran amenaza se siente en el momento en que Jose es promovido en el trabajo, lo que significa que él no necesitará más el uniforme. Sorprendiendo a los compañeros, renuncia y se mantiene en casa, sin condiciones de buscar un nuevo trabajo.

Desde el punto de vista del psicoanálisis, el cuerpo propio no se reduce al organismo real, sino se extiende más allá y hacia fuera del cuerpo del sujeto, a

\footnotetext{
${ }^{1}$ Con relación a la distinción entre locura y psicosis, destacamos el artículo "Formulaciones sobre la causalidad psíquica" (Lacan, 1946/1998a), que, además de una importante referencia para la discusión de la temática organogénesis-psicogénesis, señala que la locura, fenómeno de orden imaginario, es común a las dos estructuras (neurosis y psicosis).

${ }^{2}$ En la paranoia, la metáfora delirante cumple, en cierta medida, esa función.
} 
partir de la articulación de los registros imaginario y simbólico. Se trata aquí de la idea freudiana de un yo corporal como proyección de una superficie y que depende de lo que Lacan denomina lenguaje-órgano (1975-1976/2007). El cuerpo, sea como sea, está siempre relacionado a algo que ex-siste más allá del envoltorio corporal. Cuerpo-morada, punto de referencia que posibilita una morada-construcción. La sensación del cuerpo propio constituye una geografía que tiene la función de protección, de barrera expandida para lo que es amenazador y externo. Como indica Lacan (1972-1973/1985b) el espacio no es de origen empírico, no porque él correspondería a una intuición pura a priori, como indica Kant, sino porque él se estructura como lenguaje. El sujeto se constituye por una exterioridad íntima, que involucra algo más allá de sí mismo, o sea, de lugar que expande sus límites, incluyendo una heterogeneidad.

Como efecto del desencadenamiento psicótico, es común verificar la necesidad de recogimiento por parte del sujeto a una especie de territorio originario, que delimita un área primaria de protección. Se puede considerar que la duplicación del cuerpo y la delimitación de un territorio son, en ciertas psicosis, las formas de solución y de estabilización mínima posibles.

Retomando Heidegger, "habitar es permanecer pacificado en la libertad de una pertenencia" (Heidegger, 1954/2008, p. 129). Y, según indica Lacan, habitar es habitar el lenguaje, resguardarse, guarecerse. Ello apunta a la importancia de una clínica que reconozca la función de la construcción de lugares y vínculos sociales en el tratamiento de las psicosis.

\section{Referencias}

Freud, S. (1977a). Notas psicanalíticas sobre um relato autobiográfico de un caso de paranoia (dementia paranoides). In Edição Standard Brasileira das Obras Psicológicas Completas de Sigmund Freud (v. XII, pp. 15-107). Rio de Janeiro: Imago. (Trabalho original publicado em 1911).

Freud, S. (1977b). O inconsciente. In Edição Standard Brasileira das Obras Psicológicas Completas de Sigmund Freud (v. XIV, pp. 185-245). Rio de Janeiro: Imago. (Trabalho original publicado em 1915).

Freud, S. (1977c). A perda da realidade na neurose e na psicose. In Edição Standard Brasileira das Obras Psicológicas Completas de Sigmund Freud (v. XIX, pp. 227-234). Rio de Janeiro: Imago. (Trabalho original publicado em 1924). 


\section{CONFERÊNCIA/LECTURE}

Freud, S. (1977d). A negativa. In Edição Standard Brasileira das Obras Psicológicas Completas de Sigmund Freud (v. XIX, pp. 293-300). Rio de Janeiro: Imago. (Trabalho original publicado em 1925).

Freud, S. (1977e). Esboço de psicanálise. In Edição Standard Brasileira das Obras Psicológicas Completas de Sigmund Freud (v. XXIII, pp. 165-237). Rio de Janeiro: Imago. (Trabalho original publicado em 1940[1938a]).

Freud, S. (1977f). A divisão do ego no processo de defesa. In Edição Standard Brasileira das Obras Psicológicas Completas de Sigmund Freud (v. XXIII, pp. 305-312). Rio de Janeiro: Imago. (Trabalho original publicado em $1940[1938 b])$.

Freud, S. (2007a). La negación. In Obras Completas (v. XIX, pp. 249-257). Buenos Aires/ Madrid: Amorrortu. (Trabalho original publicado em 1925).

Freud, S. (2007b). La escisión del yo en el proceso defensivo. In Obras Completas (v. XXIII, pp. 271-278). Buenos Aires/Madrid: Amorrortu. (Trabalho original publicado em 1940[1938]).

Freud, S. (2007c). Esquema del psicoanálisis. In Obras Completas (v. XXIII.pp. 135-209). Buenos Aires/Madrid: Amorrortu. (Trabalho original publicado em 1940[1938a]).

Heidegger, M. (2008). Ensaios e conferências. Petrópolis, RJ: Vozes. (Trabalho original publicado em 1954).

Lacan, J. (1985a). O seminário. Livro 3. As psicoses. Rio de Janeiro: Jorge Zahar. (Trabalho original publicado em 1955-1956).

Lacan, J. (1985b). O seminário. Livro 20. Mais ainda. Rio de Janeiro: Jorge Zahar. (Trabalho original publicado em 1972-1973).

Lacan, J. (1988). O seminário Livro 7. A ética da psicanálise. Rio de Janeiro: Jorge Zahar. (Trabalho original publicado em 1959-1960).

Lacan, J. (1998a). Formulações sobre a realidade psíquica. Em Escritos. Rio de Janeiro: Jorge Zahar. (Trabalho original publicado em 1946).

Lacan, J. (1998b). Resposta ao comentário de Jean Hyppolite sobre a "Verneinung" de Freud. In Escritos. Rio de Janeiro: Jorge Zahar. (Trabalho original publicado em 1954).

Lacan, J. (1999). O seminário. Livro 5. As formações do inconsciente. Rio de Janeiro: Jorge Zahar. (Trabalho original publicado em 1957-1958).

Lacan, J. (2007). O seminário. Livro 23. O sintoma. Rio de Janeiro: Jorge Zahar. (Trabalho original publicado em 1975-1976).

Leite, S. (2009). Psicoses e Instituição: uma leitura psicanalítica. Projeto de Pesquisa de Professor Visitante do Programa de Pós Graduação em Psicanálise da UERJ. 
Leite, S. (2011). Angústia. Coleção Passo a Passo. Rio de Janeiro: Jorge Zahar.

Miller, J.-A. (2003). A invenção psicótica. Opção Lacaniana, Revista Brasileira Internacional de Psicanálise, São Paulo, n. 36, p. 6-16.

Rabinovich, D. (2005). A angústia e o desejo do Outro. Rio de Janeiro: Cia. de Freud.

\section{Resumos}

(Habitar, construir, existir: algumas considerações sobre o corpo nas psicoses)

A partir de Freud, de Lacan e de um importante ensaio de Heidegger, que trata do tema do habitar, destaca-se a questão da inscrição do corpo - primeira morada - a partir do encontro com o Outro. A ausência do significante da falta impede o psicótico de, em certas situações, se apropriar do sentido fato que produz o desencadeamento da psicose. A invenção do corpo próprio resgata o sujeito da errância produzida pelo rompimento da realidade e produz a estabilização na psicose.

Palavras-chave: Corpo, psicoses, espaço, estabilização

(To inhabit, to build, to exist: considerations concerning the body in psychoses)

Based on Freud, Lacan and on an important essay by Heidegger dealing with the topic of inhabiting, the question concerning the inscription of the body - the first home - is highlighted following an encounter with the Other. The absence of the meaning of lack prevents the psychotic person, in certain situations, from appropriating for himself the sense fact that leads to the onset of psychosis. The invention of the personal body saves the subject from the wanderings produced by the disruption of reality, and leads to stabilization of the psychosis.

Key words: Body, psychoses, space, stabilization

(Habiter, bâtir, exister: quelques considérations sur le corps dans les psychoses)

Depuis Freud, Lacan et un important essai de Heidegger traitant du thème de l'habiter, on distingue la question de l'inscription du corps - la première demeure à partir de la rencontre avec l'Autre. L'absence du signifiant du manque empêche le psychotique, dans certains cas, de s'approprier le sens, fait qui produit le déclenchement de la psychose. L'invention du corps lui-même délivre le sujet de l'errance produite par la rupture de la réalité et produit la stabilisation dans la psychose.

Mots clés: Corps, psychoses, espace, stabilisation 


\section{CONFERÊNCIA/LECTURE}

(Wohnen, bauen, existieren: einige Überlegungen zum Körper in Psychosen)

Freud, Lacan und ein wichtiger Aufsatz Heideggers, der sich mit dem Thema Wohnen beschäftigt, bilden die Grundlage unserer Analyse über die Inskription des Körpers - der erste Wohnort — ab der Begegnung mit dem Anderen. Die Abwesenheit des Signifikanten des Mangels hindert den Psychotischen daran, in bestimmten Situationen, sich den Sinn anzueignen, ein Umstand der den Ausbruch der Psychose erzeugt. Die Erfindung des eigenen Körpers rettet das Subjekt vom Umherirren, welches durch den Bruch mit der Realität erzeugt wurde und erzeugt eine Stabilisierung in der Psychose.

Schlüsselwörter: Körper, Psychosen, Raum, Stabilisierung

（住留, 构建, 存在：对肉体与精神世界的关系的思考）

佛罗依德, 拉孔, 甚至海德格尔的一篇重要的文章, 都探讨了关于精神在 肉体的住留问题, 特别是关于肉体和精神的相遇, 肉体 “注册” 成为精神的第 一栖息地。专家指出, 精神和肉体的缺乏有意义的协调, 在某些情况下, 会阻 碍精神驾驭感知, 从而引发精神病。我们认为对肉体的干预是解决精神和肉体 关系不协调的一种办法, 一种稳定精神病症的办法。

关键词: 肉体, 精神病, 空间, 稳定。

Citação/Citation: Leite, S. (2016, junho). Habitar, construir, existir: algunas consideraciones sobre el cuerpo en las psicosis. Revista Latinoamericana de Psicopatologia Fundamental, 19(2), 214-224.

Editores do artigo/Editors: Prof. Dr. Manoel Tosta Berlinck e Profa. Dra. Sonia Leite

Recebido/Received: 15.4.2015/ 4.15.2015 Aceito/Accepted: 18.6.2015 / 6.18.2015

Copyright: (C) 2009 Associação Universitária de Pesquisa em Psicopatologia Fundamental/ University Association for Research in Fundamental Psychopathology. Este é um artigo de livre acesso, que permite uso irrestrito, distribuição e reprodução em qualquer meio, desde que o autor e a fonte sejam citados / This is an open-access article, which permits unrestricted use, distribution, and reproduction in any medium, provided the original authors and sources are credited. 
Financiamento/Funding: A autora declara não ter sido financiada ou apoiada / The author has no support or funding to report.

Conflito de interesses/Conflict of interest: A autora declara que não há conflito de interesses / The author has no conflict of interest to declare.

\section{Sonia Leite}

Psicanalista; Membro do Corpo Freudiano Escola de Psicanálise (Rio de Janeiro, RJ, Br.); Doutora em Psicologia Clínica pela Pontifícia Universidade Católica do Rio de Janeiro - PUCRio; Coordenadora Adjunta da Residência Multiprofissional em Saúde Mental da Secretaria de Estado de Saúde/Universidade do Estado do Rio de Janeiro - SES-RJ/UERJ; Editora da Revista Latinoamericana em Psicopatologia Fundamental (São Paulo, SP, Br); Membro da Associação Universitária de Pesquisa em Psicopatologia Fundamental - AUPPF (São Paulo, SP, Br); Autora do livro Angústia da coleção Passo a Passo da Jorge Zahar, e de diversos artigos. Rua Conde de Bonfim, 232/712

20520-051 Rio de Janeiro, RJ, Br.

e-mail: soniacleite@uol.com.br

This is an open-access article, which permits unrestricted use, distribution, and reproduction in any medium for non-commercial purposes provided the original authors and sources are credited. 